\title{
The performance evaluation for rivet bonded joints in production and machine maintenance
}

\author{
Natalia Baurova ${ }^{1, *}$, Alexander Anoprienko ${ }^{1}$, and Yulia Romanova $^{1}$ \\ ${ }^{1}$ Moscow Automobile and Road Construction State Technical University (MADI), 125319, Moscow, \\ Leningradskii pr.64, Russia
}

\begin{abstract}
The paper deals with the studies on the serviceability and performance of rivet bonded joints produced with the use of thermoplastic hot-melt adhesives. Thermoplastic hot-melt adhesives are compared with conventional epoxy adhesives. The performance evaluation of different adhesive materials by dismantling of rivet bonded joints is fulfilled. The time necessary for each operation of the process is considered. The algorithms are provided for finding the design and engineering solution when replacing the conventional process of riveting by rivet bonding in production and machine maintenance.
\end{abstract}

The riveting technique is wildly used in aircraft engineering, mechanical engineering, and car manufacturing during assembly of dissimilar materials or those with poor weldability, heat-treated or finish-machined precision components. All of above cannot be heat-treated, it is therefore extremely difficult or impossible at all to apply traditional welding [1]. The riveting technique is also applied during assembly of components being used in strong vibration and shock environments [2].

The necessity of providing further joint sealing is a serious problem with the riveting technique. However, seal failures may still occur for there is a major risk of electrolytic corrosion. Rivet setting for the assembly of large machine parts with numerous holes is difficult. The mismatch of holes takes place because of the displacement of plates. Thus, face sealing does not provide the complete solution to the problem.

Today the riveting technique is increasingly being replaced by rivet bonding during assembly of large thin-walled structures in such industries as mechanical engineering, aircraft engineering, and car manufacturing [2-4].

Rivet bonding provides the manufacture of structures with superior characteristics. It is a hybrid joining technique which combines adhesive bonding with riveting.

Applying adhesives to the bond when producing rivet bonded joints made it possible to considerably improve the following bonding characteristics: corrosion resistance, strength and life time, especially under fluctuating load. The drawbacks commonly found in the rivet bonding technique can be significantly reduced through further design development of rivet bonded joints.

\footnotetext{
*Corresponding author: nbaurova@mail.ru
} 
When applying rivet bonding in car manufacturing special attention is paid to joint performance. Performance is the reduced labour-intensive costs, potential reassembly (including affected component replacement) and, as a result, the increased serviceability. In spite of the fact that serviceability is one of the main characteristics connected with the reliability, at present there are no experimental methods of joint performance and serviceability determination.

The performance of rivet bonded joints is evaluated by the labour intensity of the joints and the time necessary for the complete removal of the adhesive from the metal service of the sample after drilling.

The choice of the instrument effects the quality and labour intensity of the rivet bonded joints greatly.

For rivet installation special instruments are necessary. The type of the instrument used depends on the type of the rivet (a self-piercing rivet or a pop rivet) and production.

For self-piercing rivet installation in mass and medium production press riveting machines are used. Great speed of rivet installation in assembly lines, precise positioning of rivets and, as a result, the increased quality of the process are specific characteristics of this instrument. Hand pneumatic rivet guns are used for small batch or individual production. The creation of great downward force necessary for closing head formation is the peculiarity of this instrument. The use of other hand instruments does not provide this process. Hand pneumatic rivet guns have great portability without permanent mounting in the workshop. Due to the holding magnet in the nozzle this instrument may be used in different positions without paying attention to rivet escape. Hand press riveters are also used in car maintenance. The main drawback of this tool is the necessity of a portable air compressor or a compressed air system.

For pop rivet installation in mass and medium batch production big automatic conveyer riveting machines are used. The specific feature of this instrument is the constant production of rivet bonded joints in flow production of frames.

Highly skilled workers are required to operate and maintain the machines.

For pop rivet installation hand rivet guns are used in small and individual production. They can be pneumatic, electric or mechanical (put into operation by the press force of the hand lever). This instrument is characterized through easy handling, portability, no need in special user qualification, availability in the market and low price. Accumulator riveters are mostly used in machine maintenance for installation of pop rivets.

A considerable decrease in force applied by the worker in contrast to the mechanical hand rivet gun, autonomous riveting without any electric current supply or air compressed system along with high availability are typical for this tool.

Regardless of the instrument used, the process of installation of pop rivets is the following: resting the rivet collar the tool grabs the rivet shank with the chuck jaws pulling the rivet head through the rivet body, widening it and forming the blind head of the rivet.

The main demands for the adhesive when forming a rivet bonded joint are [1, 4-5]:

- required deformation-strength properties, great heat and working environment resistance, durability of the joint;

- $\quad$ required technological properties (curing temperature and time, pressure applied, viscosity (in case of initial liquid state of adhesive);

- $\quad$ compatibility of the adhesive with the materials to be joint.

Thermoreactive epoxy adhesives are traditionally used to create joints. The main application advantages of such adhesives are good joint sealing and corrosion resistance, no need for heating and lack of stress concentration in the joint area. The drawbacks include high requirements imposed on the quality of surface preparation, a long time of curing, toxicity and the difficult process of dismantling [6]. 
The high strength of adhesive and lack of thermoplasticity require additional power load and extra tools that significantly complicates dismantling. Furthermore, the faying surfaces of the bonded parts may be damaged while dismounting.

Technological demands are easily met, as a rule, only in repairing of such units as car frames, doors, trunks and other removable units including trim package. However, if the car body or some of its parts (a floor, a roof or side panels) need repairing, the demands, especially in standard rivet bonding with the use of epoxy adhesives are not satisfied. This causes a significant increase in repair cost.

An alternative type of adhesives applied to create joints is hot-melt adhesives. They are thermoplastic polymers. Initially solid, hot-melt adhesives get melted and viscous-flow at elevated temperatures. Once they cool, they revert to the original solid state. Depending on a brand, bonding temperatures range between $100-200^{\circ} \mathrm{C}$.

The advantages of hot-melt adhesives applied together with rivet bonded joints are that they are easily removed and provide increased strength and stiffness to structures under static, dynamic and vibration loads $[2,7]$. The change of epoxy adhesives to less durable but more technological hot-melt ones provides the opportunity to solve the problem of joint serviceability.

In spite of hot-melt adhesive application simplicity their use causes a great number of technological problems. The most difficult problem is fast cooling of the hot-melt adhesive in its direct contact with a cold metal surface [7].

Kinetics of this process depends on thermophysical properties of the hot-melt adhesive used as well as on the melt temperature. Another important factor is the temperature of parts being riveted. However, it is equal to the air temperature in the workshop. If the width of the adhesive layer is not enough, the cooling process will occur at a high rate, so that the worker could not be able to install the rivet in proper time and perform the riveting process.

At present hybrid joints combining adhesive bonding with rivet joints are created in one of three possible ways $[1,4]$ :

- $\quad$ the sequential method (installing rivets after the adhesive layer has hardened);

- $\quad$ the fixing method (installing rivets before adhesives have cured);

- $\quad$ the injection method (joining parts with a rivet joint before injecting the adhesive into the gap between the components).

The fixing method is widely used for automotive body repairs. The principle of the technique is that of installing rivets after adhesive application but before its hardening. This technology provides a higher level of joint efficiency compared with adhesive bonding, riveting or the sequential method of rivet bonding when rivets are installed after the adhesive has cured. The fixing method also enables to use the most technological adhesives that provide a strong adhesive layer. The main drawbacks of the method are the rivet tool contamination caused by excessive uncured adhesive and the increased drill wear.

The simplicity of dismantling is produced by the fact that the hot-melt adhesive transforms into a liquid condition and loses its viscosity when heated.

The sequence of dismantling operations for rivet bonded joints created with the use of hot-melt adhesives looks as follows: first, the bond line is cleaned, any dirt or paint, if there is any, is removed from the bond line. Then, rivets are drilled out (in a similar way to the process of rivet joint dismantling) [7]. After that the bond line is being heated with the hot air gun until the adhesive gets melted. When heated it becomes viscous-flow and joint surfaces get separated without any application of load. The rest of molten adhesive is removed from the plate surface with some cloth. The result is a clean and tidy surface suitable for repeated bonding or riveting. 
If after dismantling the next riveting of these elements is planned, it is possible not to remove the hot-melt adhesive from the surface and perform riveting with the help of the "old" adhesive which when heated gets viscosity and capability of hardening once more.

For comparative analysis of the joint performance two types of adhesive materials were chosen: thermoplastic hot melt adhesive and thermoreactive epoxy adhesive. Samples of these joints were prepared for shear tests $[1,7]$ (fig.1).

Evaluation of the application performance of the chosen adhesives in dismantling of rivet bonded joints was made concerning the time required for each operation of technological process. The results are given in table 1.

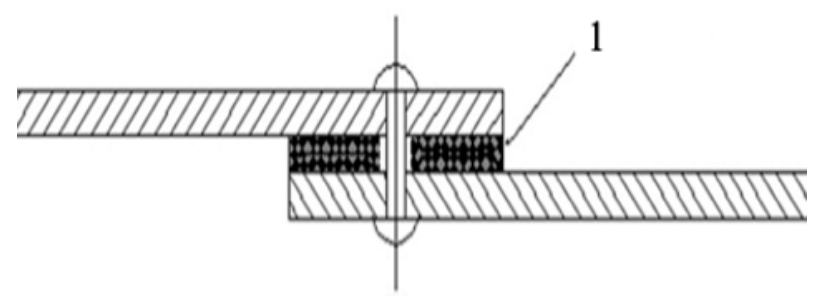

Fig. 1. The appearance of rivet bonded joints to be tested: 1- bond line

Table 1. Time required to perform technological operations with the use of different adhesives

\begin{tabular}{|c|c|c|c|}
\hline \multirow{2}{*}{ № } & Operation & \multicolumn{2}{|c|}{ Time, min } \\
\cline { 2 - 4 } & Surface preparation & $\begin{array}{c}\text { Hot-melt } \\
\text { adhesive }\end{array}$ & $\begin{array}{c}\text { Epoxy } \\
\text { adhesive }\end{array}$ \\
\hline 1 & Adhesive preparation & \multicolumn{2}{|c|}{1,5} \\
\hline 2 & Adhesive application & 1,5 & 10 \\
\hline 3 & Rivet positioning in the holes & \multicolumn{2}{|c|}{0,2} \\
\hline 4 & the closing head & 1,5 & 0,5 \\
\hline 5 & Tightening of riveted parts and creation of & 10 & 1,2 \\
\hline 6 & Excessive adhesive removal & 1 & 10 \\
\hline 7 & Adhesive curing & \multicolumn{2}{|c|}{} \\
\hline 8 & Working place cleaning & \multicolumn{2}{|c|}{10} \\
\hline
\end{tabular}

As is seen from above, hot-melt adhesives require extra time for some operations, particularly for applying and removal of excessive amount of adhesive for the use of force or reheating is necessary to perform this task. Epoxy adhesives also require extra time for adhesive preparation (mixing the epoxy with the hardener) before each application. The need for epoxy hardening is the most important factor to consider in terms of time spent (it may last up to 24 hours). In contrast with epoxies, hot-melt adhesives get cured much faster (approx. $10 \mathrm{~min}$ ).

Furthermore, the use of hot-melt adhesives allows to minimize the number of possible faults occurring by rivet bonded joint dismantling. The analysis of faults, their causes and possible remedies is given in table 2 . 
Table 2. Typical faults by rivet bonded joint dismantling, causes and remedies

\begin{tabular}{|c|l|l|l|}
\hline № & \multicolumn{1}{|c|}{ Fault } & \multicolumn{1}{|c|}{ Cause } & \multicolumn{1}{c|}{ Remedy } \\
\hline 1. & Rivet distortion & $\begin{array}{l}\text { Diameter of hole is more } \\
\text { than required }\end{array}$ & $\begin{array}{l}\text { It is necessary to choose the rivet with } \\
\text { the proper diameter so that the rivet } \\
\text { could be placed into the holes without } \\
\text { being loose. By dismantling the rivet is } \\
\text { removed through oblique shock against } \\
\text { the rivet shank }\end{array}$ \\
\hline 2. & $\begin{array}{l}\text { Deformation } \\
\text { (bend) of rivet } \\
\text { shaft }\end{array}$ & $\begin{array}{l}\text { The rivet shank of } \\
\text { excessive length } \\
\text { adhesive } \\
\text { removal }\end{array}$ & $\begin{array}{l}\text { Such rivets escape by dismantling, they } \\
\text { can be shortened to the required length } \\
\text { in advance }\end{array}$ \\
\hline 3. & $\begin{array}{l}\text { Not full } \\
\text { long time span between } \\
\text { heating and removal } \\
\text { (adhesive hardening) }\end{array}$ & $\begin{array}{l}\text { The joint having been heated to adhesive } \\
\text { melting temperatures, excessive adhesive } \\
\text { must be immediately removed with some } \\
\text { cloth }\end{array}$ \\
\hline
\end{tabular}

It is necessary to control the uniformity of the adhesive layer thickness during its application and further mounting of the framework [8-9]. Gapping between parts to be joined causes starved spots which can also occur due to air inclusions and voids in the bond line which in turn appear because of the bonding process failure. Moreover, even a negligible failure of the adhesive layer thickness will cause the misalignment of rivets.

The quality control of rivet bonding is therefore an important stage in the joint creation process. A rivet bonded joint of high quality is characterized through the uniform and faultfree (non-porous) adhesive layer between the rivets, rivet placing in axial alignment, precise rivet positioning in the hole, the match between the closing head and the die head.

When creating rivet bonded joints with epoxy adhesives it is also necessary to observe the microclimatic parameters of a working area. High humidity causes curing to decelerate or even stop whereas hot-melt adhesives are moisture resistant.

The transition from conventional riveting to rivet-bonding requires changes in the technical documentation [8]. By rivet bonding development the optimal design solution is expected to be at the car manufacturing plant or maintenance centre that includes all the joint parameters with the maximum allowable limits. The design solution algorithms, the essence of which is to determine the material brands and all geometric characteristics of rivet bonded joints for a single row joint, are shown in fig. 2 .

The stresses relevant to the task being solved are marked with the help of following symbols: $\sigma_{1}, \sigma_{2}, \sigma_{3}$ and $\sigma_{4}\left(\sigma_{1}-\right.$ is the stress in the joint for the chosen type of the rivet, the material used with the joint geometry features). The maximum allowed stresses relevant to the task are marked with the symbols of $\sigma_{\text {spec }}^{1}, \sigma_{\text {spec }}^{2}, \sigma_{\text {spec }}^{3}$ and $\sigma_{\text {spec }}^{4}, \mathrm{e}, \mathrm{g}, \sigma_{\text {spec }}^{1}$ is the maximum allowed stress in the rivet joint for the rivet type chosen etc.

The technological process development (whether in production or machine maintenance) represents the engineering solution in general. Fig. 3 shows the engineering solution algorithm for rivet bonded joint creation parameters.

The principle difference between these algorithms (fig. 2, fig. 3) is the absence of quantity evaluation of the design solution at each stage in contrast to the engineering solution where such evaluation takes place at each stage of calculations [7-8].

At each stage of engineering solution development the calculation block takes place.

If the calculations performed meet the technical demands which specify the joint efficiency conditions (they are marked as «yes» in the algorithm), the calculations proceed in due course. If the calculations present that technical requirements are not met (these are marked as «no» in the algorithm), the return to the previous stage takes place where the choice 
is remade accompanied by further recalculations. Thus, the control is fulfilled on each stage of the process when finding the engineering solution and, as a rule, it is conducted with minimum costs. The correctness of calculations is confirmed (or rejected) by the mechanical test results.

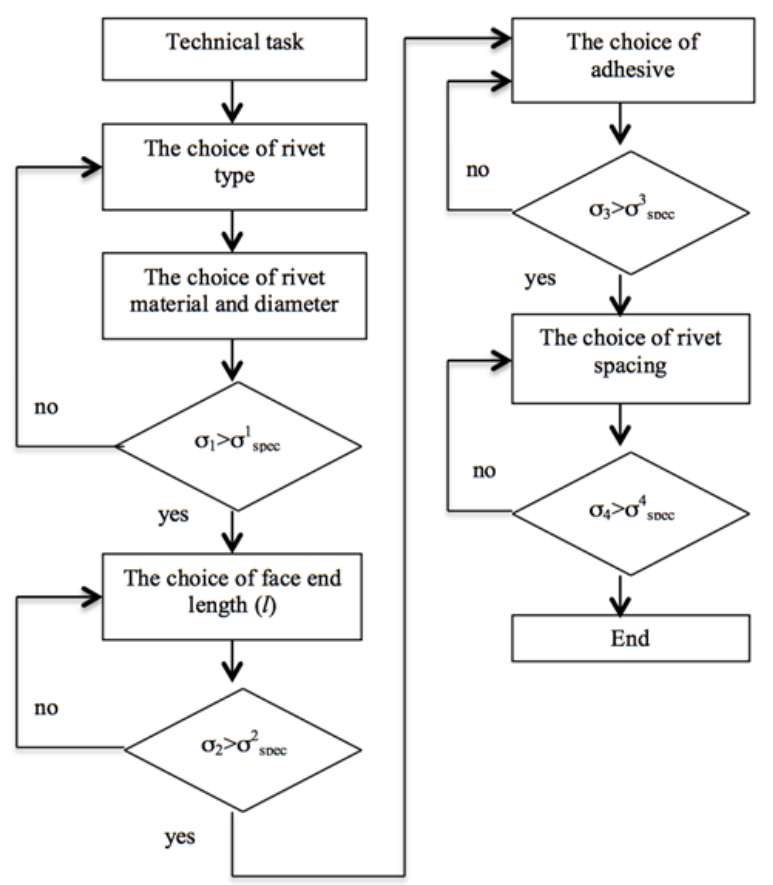

Fig. 2. The design solution algorithm for rivet bonded joints

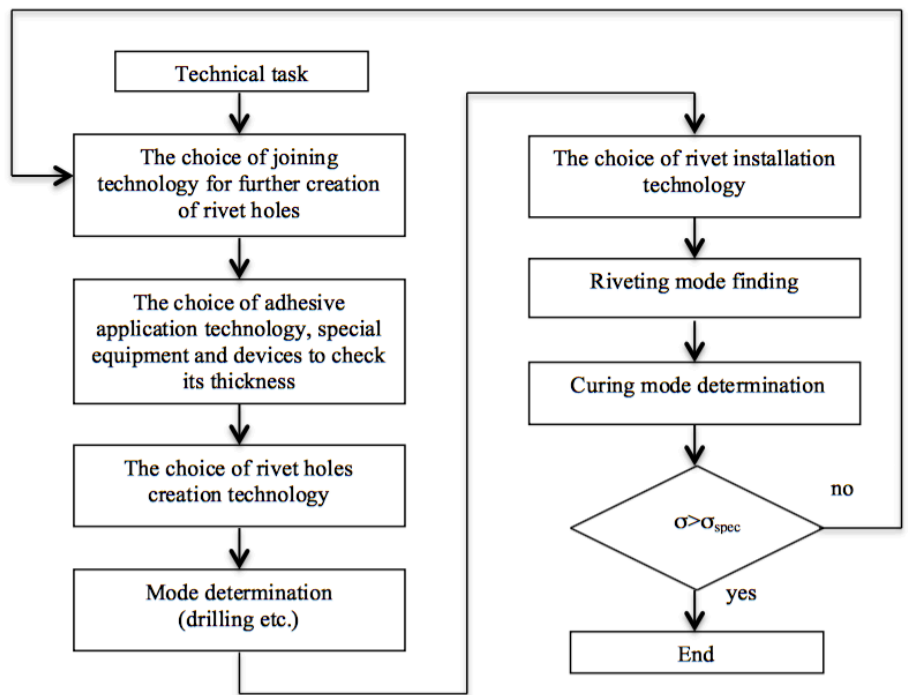

Fig. 3. The engineering solution algorithm for rivet bonded joints 
The quality control peculiarity of the engineering solutions achieved is that the loss of quality may occur at each stage, whereas the control is possible only at the end of all technological operations (fig. 3). Error accumulation is typical for this approach and it may take place on each process step and consequently result in a poorer quality of finished products $[4,9]$.

The paper suggests that the design solution should be combined with the engineering solution to reduce the time given for the development of rivet bonding modes. The design and engineering solution algorithm is shown in fig.4.
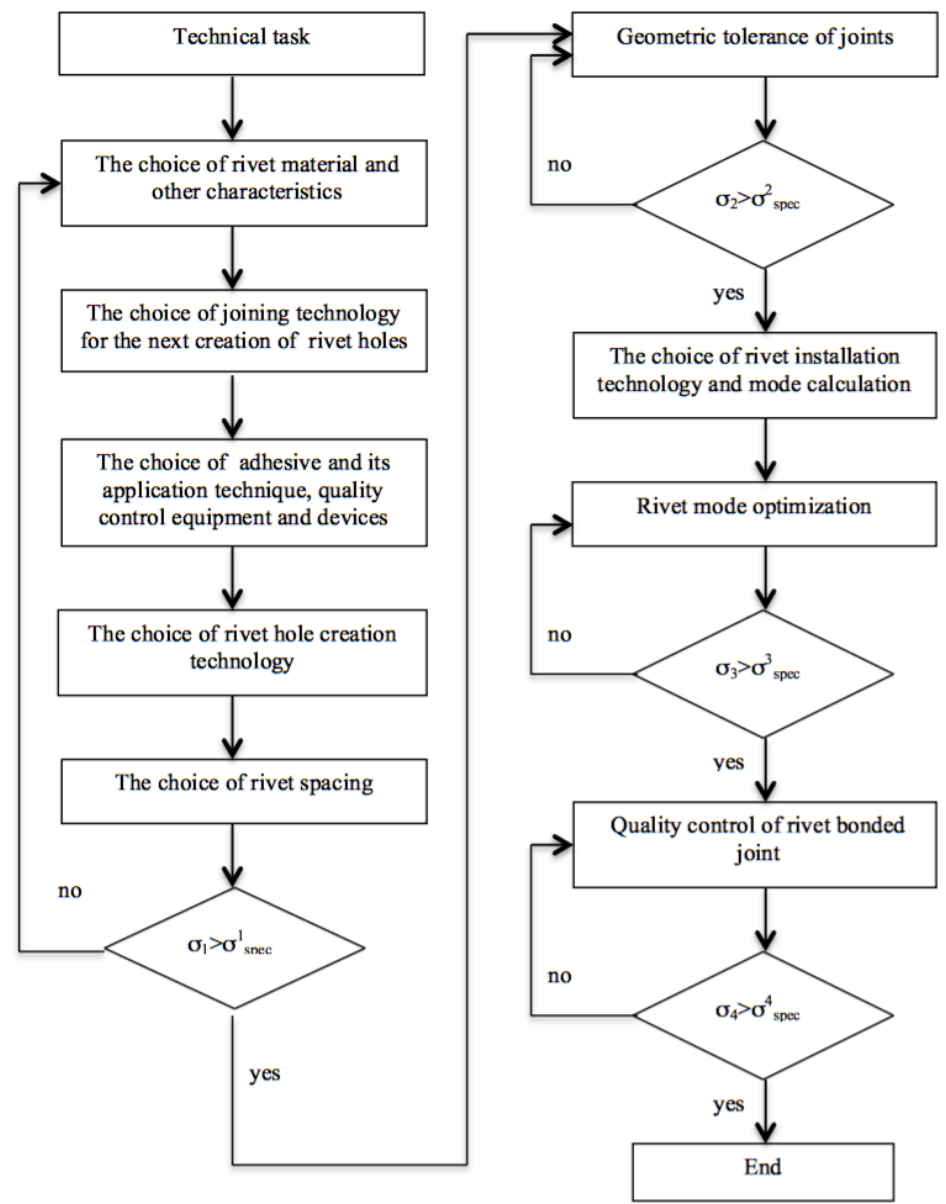

Fig. 4. Design and engineering solution algorithm in production and machine maintenance

The procedure of developing the rivet bonded joint design and engineering solution includes a sequential solution to the problem of selection and that of further analysis. The initial choice of material implies a scheme analysis that results in finding a relevant engineering solution in respect of one or more characteristics considered. If technological demands are taken into account at once, the development process reduces considerably and the quality improves. 
Under this approach the number of potential failures is minimized that significantly reduces the time allocated for maintenance technology developments along with the improvement of serviceability and joint performance.

\section{References}

1. N. Baurova, A. Anoprienko, Y. Romanova, Providing dismountable rivet bonded joints through the use of hot-melt adhesives, MATEC Web of Conferences. ICMTMTE, v. 129, 01004 (2017).

2. V.V. Grib, V.A. Zorin, R.V. Zukov, Multicriteria assessment of the theoretical state of mechanisms and machines, Repair, recovery, modernization, v. 6, pp. 19-22 (2016).

3. V.M. Prikhodko, V.A. Aleksandrov, D.S. Fatyukhin, L.G. Petrova, Effect of ultrasonic cavitation on nitride steel surface laver condition, Metal Science and Heat Treatment, v. 57(5-6), pp. 300-303 (2015).

4. A.K. Anoprienko, N.I. Baurova, A bonded-riveted technique of fabrication and machine maintenance using hot-melt adhesives, Polymer Science - Series D, v.10(3), pp. 217-220 (2017).

5. V.A. Nelyub, Characteristics of interfacial layers of polymer composite materials, Polymer Science - Series D, v. 7(4), pp. 310-312 (2014).

6. O.A. Ryakhovskii, G.V. Malysheva, A.N. Vorobev, Method for Reaching Air-Tightness of the Joint between the Casing of an Impeller Pump and Its Cover, Russian Metallurgy, v. 13, pp. 1312-1316 (2016).

7. A.K. Anoprienko, N.I. Baurova, The parametric relationship between the characteristics of production methods of bonded-riveted joints on the micro - and macroscale, Polymer Science - Series D, v.10 (3), pp. 244-246.

8. N.V. Lapina, N.I. Baurova, Feature of processing machinery parts for workability when transiting to new construction materials, Polymer Science, Series D, v. 9(3), pp. 326-330 (2016).

9. V.A. Nelyub, A.S. Borodulin, L.P. Kobets, G.V. Malysheva, Capillary hydrodynamics of oligomer binders, Polymer Science - Series D, v. 9(3), pp. 322-332 (2016). 